\title{
Televisión versus cine: La influencia de los largometrajes emitidos por TVE en la exhibición cinematográfica española (1962-1969)
}

\author{
Fátima GIL GASCÓN \\ Universidad de Burgos \\ fatimagg@ubu.es
}

Recibido: 04/02/2014

Aceptado: 10/03/2014

\begin{abstract}
Resumen
Este artículo ${ }^{1}$ tiene como objetivo analizar las relaciones entre el cine y la televisión en España durante la década de los sesenta, más específicamente entre 1962 y 1969. En concreto se trata de establecer hasta qué punto la televisión, y especialmente el cine emitido en televisión pudo influir, como sucedió en el resto de occidente, en la pérdida de público cinematográfico. Se parte de la premisa de que la televisión se presentó desde su origen como una potencial enemiga del cine que alejaba a los espectadores de las salas. Esta investigación pretende descubrir si estos planteamientos fueron reales y qué participación tuvieron en ellos la programación cinematográfica emitida por el ente público.
\end{abstract}

Palabras clave: cine, televisión, Franquismo, espectadores, relaciones

\section{Television versus cinema: National Television film broadcast's influence in Spanish cinema exhibition (1962-1969)}

\begin{abstract}
This article aims to analyze the relationship between cinema and television in Spain during the 60th, specifically between 1962 and 1969. It focuses specifically on the influence of the cinema broadcast on television and it's connection with the loss of cinema's spectators during this year in western countries. This research starts from the premise that there was a confrontation between cinema and television. Cinema watched the television like an enemy, able to get the spectator away from movie theaters. This paper aims to find the truth of those statements though the study of the relationship between cinema and television in the Francoist time.
\end{abstract}

Keywords: cinema, television, Francoist time, spectator, relationship

Referencia normalizada: GIL GASCÓN, Fátima (2014): “Televisión versus cine: La influencia de los largometrajes emitidos por TVE en la exhibición cinematográfica española (1962-1969)". Estudios sobre el Mensaje Periodístico, Vol. 20, Núm. especial, pp. 177-191. Madrid, Servicio de Publicaciones de la Universidad Complutense.

Sumario: 1. Introducción. 2. Metodología y fuentes. 3. El cine emitido por Televisión Española. 4. La industria cinematográfica en España; 4.1. La televisión y la pérdida de espectadores cinematográficos. 5. Conclusiones. 6. Referencias.

\section{Introducción}

La Guerra Civil y el aislamiento sufrido por España tras la II Guerra Mundial hicieron que la televisión se implantase décadas más tarde que en el resto de los países de

1 Este artículo es parte de la investigación iniciada por la autora en el marco del proyecto "Televisión y cultura popular durante el franquismo: programación, programas y consumo televisivo (1956-1975)" reconocido y financiado por el Ministerio de Ciencia e Innovación (ref. HAR2011-27937) y del Grupo de investigación Complutense Historia y Estructura de la comunicación y del entretenimiento (940439). 
occidente. En Francia, Inglaterra, Alemania y EEUU este medio comenzó su andadura en la década de los 30 aunque no fue hasta después de la contienda cuando se consolidó plenamente (Baget, 1975: 10-12). Los años cincuenta presentan una televisión occidental en pleno desarrollo: En 1951 se produce la primera transmisión de Nueva York a San Francisco (coast to coast) (Baget, 1965: 23) y dos años después la BBC retransmite la coronación de la Reina Isabel II inaugurándose la Eurovisión (Hankard, 1965: 37).

En esta época comenzaba en España la etapa experimental. En 1953 un reducido número de espectadores madrileños podían disfrutar los jueves por la tarde de algunas horas de emisión (May, 1959: 282-283). Este público no solo era escaso por motivos técnicos. No hay que olvidar que el país que acogió los primeros pasos de Televisión Española comenzaba, tímidamente a superar unos graves problemas económicos y que, tan solo un año antes de estas primeras emisiones, se había finalizado oficialmente el racionamiento.

Cuando el 26 de octubre de 1956 a las seis y cuarto de la tarde comenzaron las primeras emisiones para los seiscientos receptores existentes en el área metropolitana de Madrid, las televisiones occidentales estaban plenamente consolidadas: habían empezado a experimentar con los primeros sistemas de color y de grabación en video (Abramson, 2003: 65-68) y ya se habían enfrentado a los ataques y las críticas de diversas entidades como, por ejemplo, la industria del cine.

Los cines occidentales, principalmente productores, exhibidores y distribuidores, mantuvieron una desigual relación con la televisión durante sus primeras décadas de vida. El nuevo medio fue visto como el causante de la disminución de espectadores en las salas de cine y, por tanto, como un poderoso enemigo. No en vano, André Bazin, en su artículo titulado "Will cinemascope save de film industry?" publicado en 1953 señalaba ya a la televisión como una de las principales causas de la crisis de Hollywood tras la II Guerra Mundial (Bazin, 1953).

Esto era más elocuente teniendo en cuenta las cifras manejadas por la industria cinematográfica occidental. En Reino Unido se pasó de 1636 millones de espectadores en 1946 a 343 en 1964, mientras que el número de televisores aumentaba de 330.000 a 13.155000 en esos mismos años (Otero, 2006: 59-60).

Según las cifras del International Televisión Almanac, en 1946 había 6.476 receptores en EEUU, seis años después habían aumentado a 6.096.280 y a finales de la década se contabilizaron 49.000.000 televisores. Al mismo tiempo, el número de espectadores se reducía de 90 millones en 1946 a 45 en el año 53. (Romaguera y Alsina, 1998: 558)

Durante estas décadas la venta de entradas se redujo un 20\% en Alemania, un 33\% en Francia y un $25 \%$ en los Países Bajos (Hankard, 1965: 37). Pese a que la disminución del número de espectadores en las salas de cine no era consecuencia exclusiva de la implantación de la televisión sino, más bien, de un estilo de vida y ocio diferente, lo cierto es que el nuevo medio se erigió como el principal enemigo al que culpar de la situación.

En la década de los cincuenta, los cines europeos plantearon diversas tácticas para evitar la pérdida de público que comprendía, sobre todo, la implantación de medidas 
protectoras y la prohibición de emitir en televisión películas con una determinada antigüedad que pasaba de los cinco años en Francia, diez en Inglaterra o cuatro en Italia (Otero, 2006: 58-62).

En EEUU la estrategia fue doble. Por un lado se intentó proteger la producción cinematográfica con el fin de que ésta no fuera emitida por televisión mientras pudiera tener una explotación comercial. Y por otro, se establecieron relaciones con las televisiones consiguiendo pingües beneficios con la venta y alquiler de los derechos de emisión de filmes antiguos (Moreno Torres, 2005). Poco después comenzaría el intercambio de profesionales de un medio a otro y la producción de filmes destinados a la pequeña pantalla.

La televisión en España se implantó en un momento en el que el conflicto entre cine y televisión en occidente era muy evidente. Esto provocó que el medio naciera con una serie de prejuicios producto, no de la propia experiencia, sino del sentir de los países afectados. Pese a las enormes diferencias existentes entre este país y el resto de las potencias europeas y EEUU, la confrontación entre la televisión y el cine se planteó como un hecho cierto. Una realidad que respondía no tanto a datos objetivos como a las vivencias experimentadas por las industrias cinematográficas de estas naciones extranjeras.

\section{Metodología y fuentes}

Este artículo tiene como objetivo analizar la posible influencia de la programación televisiva, más concretamente la emisión de largometrajes, en la progresiva pérdida de espectadores que sufrió la industria cinematográfica española en los últimos años de la década de los sesenta².

Este punto de partida sitúa el estudio en la línea de trabajo de la Historia de la Comunicación Social al asumir la comunicación como el resultado de los efectos conjuntos de los medios en un ámbito espacial y temporal determinados (Montero y Rueda, 2001:18).

Esta investigación se ha realizado a partir del análisis de diversos documentos. Uno de ellos es la revista Tele Radio, publicación semanal editada por Televisión Española. Para descubrir los cauces que estructuraron las relaciones entre ambas pantallas se ha procedido al estudio de los números relativos a la época de estudio ${ }^{3}$ haciendo especial hincapié en los artículos referidos a las concomitancias entre ambos medios. También se ha realizado una sistematización de los filmes emitidos (números de espacios de cine, género, nacionalidad, año de producción) con el fin de comprobar la presencia e importancia del séptimo arte en la televisión y, por tanto, determinar la posible influencia de la misma en la asistencia o ausencia del público en las salas de cine.

2 "Como defensa elemental, tomamos el acuerdo de que no se proyecten en los aparatos televisores películas cinematográficas comerciales recientes, porque ellos supondría trasladar las salas de proyección a los hogares. pero los programas específicos de la televisión no nos inquietan, porque se trata de diversiones diferentes y compatibles". Ya en 1960 Cesáreo González, productor cinematográfico, señalaba la emisión de películas cinematográficas como un posible problema para la exhibición cinematográfica. Tele Radio, año 1960, n 106

3 Del número 201 (1 al 7 enero 1962) al número 626 (29 diciembre 1969 al 4 enero 1970) 
Este estudio parte de la premisa de que la televisión fue considerada una peligrosa rival de la industria del cine capaz de sustraer espectadores a los locales de exhibición. Para comprobar la veracidad de esta afirmación se ha acudido a dos documentos muy distintos. Por un lado y con el objeto de confirmar el enfrentamiento entre ambos medios se han analizado los números publicados en 1962, año en el que comienza el estudio, de las revistas Film ideal ${ }^{4}$, Nuestro cinema ${ }^{5}$ y Primer Plano ${ }^{6}$. Por el otro, y como modo de interpretar la posible de pérdida de pantallas y espectadores $\mathrm{y}$, sobre todo, sus causas se ha recurrido a anuarios de cine y a diversas encuestas sobre consumo de medios?.

La investigación se ha completado con la consulta de la literatura de estos años relativa a la televisión y la exhibición cinematográfica ${ }^{8}$ así como a la escasa bibliografía actual sobre el tema tratado ${ }^{9}$ El análisis cuantitativo y cualitativo de las fuentes utilizadas ha permitido ahondar en la mentalidad de la época sobre el fenómeno televisivo así como en los difíciles mecanismos de relación entre ésta y el cine.

Se ha escogido la década de los 60, concretamente el período de 1962 a 1969 por ser la época en la que Fraga estuvo al frente del Ministerio de Información y Turismo, organismo del que dependían ambos medios. Durante estos años suceden importantes acontecimientos en el ámbito televisivo: se inauguran los estudios de Prado del Rey en el año 1964, se suprime en 1965 el "impuesto de lujo" que grababa el televisor lo que permite un mayor acercamiento de la población a este aparato (Baget, 2001) y se inaugura la segunda cadena de televisión.

Estos son también años convulsos para el cine. La compleja organización impuesta por el Régimen en materia de cinematografía unida a los problemas propios de una sociedad en un proceso de cambio, hicieron que en 1969 el cine español sufriera una de las crisis más virulentas de su historia. Tanto en la rama de producción como, especialmente, en la exhibición. El supuesto descenso de espectadores en las salas de cine

4 Del número 87, año VII (enero 1962) al número 110 (diciembre 1962)

5 Del número 8 (enero del 1962) al número 19 (diciembre 1962)

6 Del número 1108 (5 enero 1962) al número 1160 (28 de diciembre) año XXIII

7 AIMC; Estudio General de Medios, CD-ROM 1, 1968-1977, I.O.P. "Estudio sobre los medios de comunicación de masas en España", Madrid, 1963-1964, 3vols, I. O. P. El público opina sobre televisión, Madrid, 1965; SINDICATO NACIONAL DEL ESPECTACULO (1966): Cine español 1966, Madrid, Ediciones y publicaciones populares; SINDICATO NACIONAL DEL ESPECTÁCULO (1967): Cine español 1967,. Madrid, Ediciones y publicaciones populares.

8 BAGET; José María (1965): Televisión, un arte nuevo, Madrid, Rialp; PÉREZ CALDERÓN; Miguel (1965): La televisión de cerca, Madrid, Editorial; DIRECCIÓN GENERAL DE LA ENSEÑANZA MEDIA (1960): Nuevas técnicas en televisión y cinematografía, Madrid, Dirección general de Enseñanza Media; RODRÍGUEZ MÉNDEZ; José María (1971): Los teleadictos: (la sociedad televisual), Barcelona, Laia.

9 PALACIO; Manuel (2005): Historia de la televisión, Barcelona, Gedisa; CUEVAS, Antonio (1994): Las relaciones entre el cinema y la televisión en España y otros países de Europa, Madrid, Egeda; OTERO, José María (2006): TVE: escuela de cine, Huesca, Instituto de estudios aragoneses; CAPARROS LERA, José María (2006): "Cine y televisión", Cuadernos hispanoamericanos $\mathrm{n}^{\circ}$ 667; MORENO TORRES, Luis (2005): “Cine y televisión. Las amistades peligrosas", Comunicar, $\mathrm{n}^{\mathrm{o}} 25,2$. 
fue achacado, principalmente, a la llegada de la televisión. Demostrar la veracidad, o no, de esta cuestión es, como se ha señalado, el objetivo de este estudio.

\section{El cine emitido por Televisión Española}

Cuando televisión española comenzó su andadura en el año 56 en un pequeño chalet del paseo de La Habana, el cine y la televisión todavía no eran enemigos declarados. Prueba de ello es que, ante la imposibilidad de salir al exterior por no contar con unidades móviles para retransmitir en directo, durante los primeros meses se emitieron numerosas películas cedidas, entre otros organismos, por NODO y la embajada estadounidense (Baget, 1965: 237).

A medida que aumentaba el número de televisores y las horas de emisión, la industria cinematográfica comenzó a poner restricciones a la emisión de películas. El principal escollo al que tuvo que hacer frente televisión española en esos primeros años fue la reticencia de la industria cinematográfica a ceder películas modernas para su explotación televisiva:

"En este caso, tanto si se trata de producciones españolas como de films extranjeros doblados al español, es preciso dejar transcurrir un largo periodo, que va de los 5 a los 12 años, por regla general, hasta que se hayan extinguido los derechos del distribuidor para la pantalla grande y los films estén disponibles para la televisión. Pero es que, además, muchas de estas películas, incluso títulos para las que esta circunstancia parecería inverosímil, tienen una larga vida, y su explotación en las salas de los cines de barrio o en las pequeñas localidades se amplía bastante más allá de los plazos normales"( Tele Radio 403 del 13 al 19 septiembre, 1965)

El texto parece responder a la visión que, sobre el cine en televisión, parecía tener la industria del cine, principalmente la española: únicamente debían emitirse en la pequeña pantalla aquellas producciones que ya no resultasen lucrativas para las salas de exhibición. Esto limitaba los títulos a películas poco o nada demandadas por los espectadores, bien por su antigüedad, su sobre-explotación o su escasa calidad.

Televisión, tal y como se argumenta en numerosas ocasiones durante esta época, podía acceder a un número muy limitado de largometrajes. No solo por cuestiones comerciales sino, también, porque el diferente formato de ambos medios dificultaba el intercambio de material. Las películas solían adquirirse en lotes a los distribuidores de las grandes productoras quienes ofrecían filmes muy obsoletos cuya copias no siempre estaban en buen estado:

"Películas de largometraje... No sólo se tropieza con la resistencia desesperada de las productoras, sino que, además el material disponible es viejísimo, gastado y deficiente de sonido" (Tele Radio n ${ }^{\circ} 118,28$ de marzo al 3 abril, 1960)

El problema, pues, no solo eran los inconvenientes de la industria sino, además, la generalmente ínfima calidad técnica de las cintas, la inexistencia de una copia de la banda sonora doblada, en el caso de las películas extranjeras e, incluso, por tratarse de películas rodadas en cinemascope, un formato muy poco adecuado para la pequeña pantalla (Tele Radio $\mathrm{n}^{\circ}$ 403, 13 al 19 septiembre, 1965).

Estas cuestiones provocaron que, en los primeros años de los 60, resultase más rentable para televisión española programar telefilms que largometrajes y que, hasta 
los años centrales de esta década, la escasez, la calidad de los largometrajes programados y la continua repetición de los mismos fuera un motivo de queja constante por parte de los telespectadores (Tele Radio $\mathrm{n}^{\mathrm{o}} 237,15$ al 21 julio 1962, № 29412 al 18 agosto $1963, \mathrm{n}^{\circ} 3378$ al 14 julio 1964, $\mathrm{n}^{\circ} 21826$ febrero 4 de marzo 1962, $\mathrm{N}^{\mathrm{o}} 22623$ al 19 abril, entre otras).

Pese al manifiesto interés de los televidentes, estos condicionantes provocaron que en los primeros años de los 60 se programase muy poco cine. Durante buena parte del año 1962 se emitió apenas un largometraje a la semana, generalmente los lunes en el espacio El cine en casa -que pasó a emitirse los martes en octubre de ese año para dejar de emitirse en el año 1963-, o los domingos por la noche.

La temporada televisiva 1962/1963 comenzó con buenas intenciones, al menos en lo que al cine se refiere ya que TVE se comprometió a emitir 15 telefilms semanales. El Ente Público, sin embargo, no solo no cumplió su promesa sino que, hasta septiembre de 1963, únicamente mantuvo un espacio dedicado al cine, Sesión de noche, los domingos por la noche. La película, que no siempre se emitía, solía tener, además, un horario cambiante ${ }^{10}$.

Los filmes emitidos por Sesión de noche eran antiguos y, generalmente, de nacionalidad norteamericana. El 18 de agosto de 1963, la revista Tele Radio anunciaba la programación de este espacio para las siguientes semanas:

"TVE les ofrece en este programa, a partir de la noche de hoy, una serie de filmes de indudable interés. Todo ellos producidos por Paramount, cuyo nombre ha encabezado a lo largo de muchos años títulos inolvidables: El vals del emperador (Wilde, 1948), Medianoche (Leisen, 1939), Mi novia favorita (Cummings, 1942), El mayor y la menor (Wilder, 1942), Luna de Birmania (King, 1940), La heredera (Wyler, 1949), Un yanqui en la corte del rey Arturo (Garnett, 1949)" (Tele Radio no 294, 12 al 18 agosto)

Como puede observarse, los filmes escogidos habían sido producidos en la década de los cuarenta con desiguales resultados. Pese a que se programaron algunos títulos importantes, por lo general, se trataba de obras ligeras cuya finalidad era, básicamente, entretener.

En otoño del 63 comenzó a emitirse una película los sábados en el espacio Sesión de tarde. Estos filmes, dado el horario en el que se emitía, solían ser del gusto de todos los públicos. Eran películas producidas entre los treinta y los cincuenta, generalmente comedias o de aventuras, de nacionalidad norteamericana o inglesa ${ }^{11}$.

${ }^{10}$ Durante ese año, no se emitió la película, por ejemplo, las semanas del 19 al 24 marzo (Tele Radio 273), del 6 al 12 de mayo (Tele Radio 280) o del 26 de agosto al 1 septiembre (Tele Radio 296). A partir de noviembre dejó de programarse el largometraje para emitir en su lugar el espacio Fernández... punto y redondo (Tele Radio, $\mathrm{n}^{\circ}$ 306, 4 al 10 de octubre)

${ }^{11}$ Algunos títulos que se emitieron durante la temporada 63/64 fueron: Navidades en Julio (Sturge, 1940) (Tele Radio no 325, 16 al 22 de julio 1964); Beau Geste (Wellman, 1939) (Tele Radio n³01, 30 septiembre a 6 octubre 1963); El signo de la cruz (DeMille, 1932) (Tele Radio $\mathrm{n}^{\circ}$ 302, 7 al 13 octubre 1963); Tres lanceros bengalies (Hathaway, 1935) (Tele Radio, $\mathrm{n}^{\circ}$ 328, 6 al 12 abril 1964); Sueños de circo, (Hoffman, 1954) (Tele Radio, ${ }^{\circ}$ 329, 13 al 19 abril 1964); El huevo y yo (Erskine, USA, 1945) (Tele Radio n ${ }^{\circ} 334,18$ al 24 mayo); Los cuatro cocos (Stanley, 1929) Tele Radio $\mathrm{n}^{\circ} 336,1$ al 7 junio... 
El cine español, condicionado completamente por una industria temerosa de perder público, apenas era emitido en la pequeña pantalla tal y como se observa en las cifras aportadas por la revista Tele Radio sobre los largometrajes de la temporada $1964 / 65^{12}$. Según la publicación, televisión ofreció veintinueve filmes americanos, tres ingleses, tres franceses, uno alemán, uno austríaco y ocho españoles.

Las cifras manejadas por la revista permiten observar dos interesantes cuestiones. Por un lado, el número de películas es sustancialmente menor que el que corresponde dada la existencia de dos espacios semanales dedicados al cine. El mal estado técnico de algunos largometrajes y la dificultad de encontrar buenos títulos hizo que el cine, durante estos años, no fuera uno los hitos fuertes de la programación y, por tanto, susceptible de ser cambiado por un telefilm u otro tipo de programa siempre que fuera necesario.

Por otro, es interesante observar la escasa relevancia del cine español en el conjunto de películas emitidas. Apenas constituye un $17 \%$ de las mismas. Si el acceso a películas extranjeras eran, tal y como se ha visto, arduo y complicado, aún lo era más si se trataba de filmes españoles. No hay que olvidar que los largometrajes nacionales resultaban lucrativos no tanto por lo que podían recaudar en los cines de estreno como por la larga vida que tenían en el resto de salas del circuito cinematográfico. Esto dificultada enormemente su proyección en televisión.

La temporada 65/66 vino marcada por un buen número de largometrajes de la 20 Century Fox producidos entre 1950 y 1956. Durante estos meses se emitieron 41 películas norteamericanas, 9 inglesas, 2 francesas, 1 italiana, 1 alemana, 1 checoslovaca, 1 argentina, 1 danesa y 13 españolas.

Aunque esta temporada se observa un aumento del número de películas y una mayor variedad de nacionalidades, el porcentaje de películas españolas se mantiene prácticamente igual (18\%). Pese a que las producciones emitidas durante este año fueron más modernas, lo cierto es que se sigue manteniendo una desigual calidad en los largometrajes que, son, en su mayoría de aventuras, comedias y filmes románticos.

El comienzo de las emisiones regulares de la segunda cadena de televisión modificó sustancialmente el cine emitido por televisión. En noviembre de 1966 se crea el programa Cineclub que se emitía en el UHF los sábados por la noche. Las películas estaban organizadas por ciclos -algunos de estos ciclos fueron: ciclo Jean Cocteau, ciclo expresionismo alemán, Cine cómico, ciclo Warner $58 \ldots$... y se emitían en versión original con subtítulos, a pesar de las dificultades técnicas que esto entrañaba (Tele Radio $\mathrm{n}^{\mathrm{o}}$ 512, 16 al 22 octubre 1967).

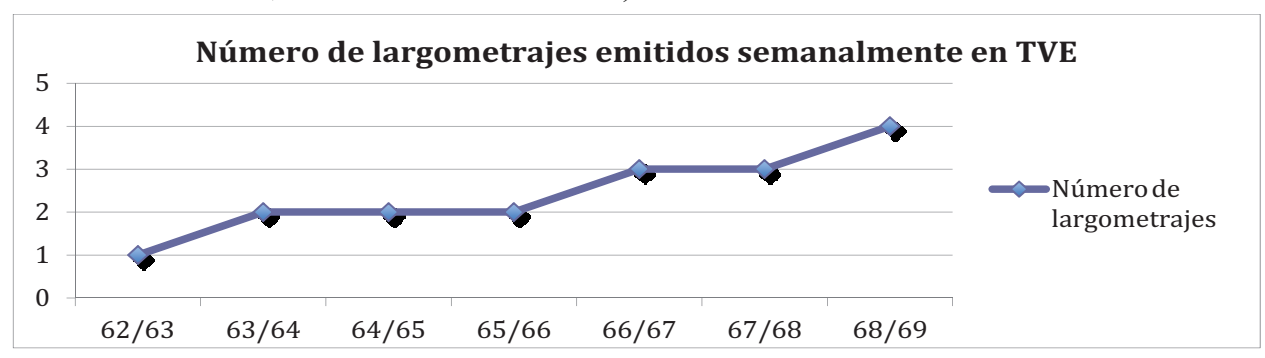

Fuente: Tele Radio. Elaboración propia

${ }^{12}$ Tele Radio 403, del 13 al 19 septiembre 1965. 
Este espacio abogaba por un cine de calidad semejante al que se proyectaba en los locales cinematográficos del mismo nombre. La película solía ser presentada por un locutor que contextualizaba la obra y que, en ocasiones, resultaba excesivamente culto (Rodríguez Méndez, 197: 124).

Hasta el año 1967 televisión española solía emitir como máximo dos filmes por semana. A partir de este año, comienzan a programarse tres largometrajes semanales en horario nocturno: los martes (Cine en casa, retirado en otoño del 67); los sábados (Cine Club) y los domingos (Sesión de noche), aunque este último fue trasladado entre agosto y noviembre de ese año a horario de tarde (Tele Radio . $^{\circ}$ 502, 7 al 13 agosto 1967). Las películas emitidas, a excepción de las que conformaban los ciclos de Cine $C l u b$, continuaban siendo filmes de entretenimiento. La temporada finalizó con casi el doble de largometrajes emitidos respecto a la temporada anterior -130 en ambas cadenas- con un ligero predominio, de nuevo, del cine norteamericano (Tele Radio $\mathrm{n}^{\mathrm{o}}$ 512, 16 al 22 octubre 1967). Esta cantidad da buena cuenta de la consolidación de los espacios cinematográficos ya que muestra una normalidad y regularidad a la hora de emitir los largometrajes programados.

Pese a que los días de emisión de las películas eran, casi siempre los mismos lunes o martes y las noches del fin de semana- lo cierto es que, salvo Sesión de noche y Cine club que tuvieron escasas variaciones, el resto de los espacios fueron apareciendo y desapareciendo en función de las necesidades de programación.

\begin{tabular}{|c|l|l|l|l|l|l|l|}
\hline Temporada & Lunes & Martes & Miércoles & Jueves & Viernes & \multicolumn{1}{|c|}{ Sábado } & \multicolumn{1}{|c|}{ Domingo } \\
\hline $\mathbf{6 2 / 6 3}$ & $\begin{array}{l}\text { Cine en } \\
\text { Casa }\end{array}$ & & & & & $\begin{array}{l}\text { Sesión de } \\
\text { noche }\end{array}$ \\
\hline $\mathbf{6 3 / 6 4}$ & & & & & & $\begin{array}{l}\text { Sesión de } \\
\text { tarde }\end{array}$ & $\begin{array}{l}\text { Sesión de } \\
\text { noche }\end{array}$ \\
\hline $64 / 65$ & & & & $\begin{array}{l}\text { Sesión de } \\
\text { tarde }\end{array}$ & $\begin{array}{l}\text { Sesión de } \\
\text { noche }\end{array}$ \\
\hline $\mathbf{6 5 / 6 6}$ & & & & $\begin{array}{l}\text { Sesión de } \\
\text { tarde }\end{array}$ & $\begin{array}{l}\text { Sesión de } \\
\text { noche }\end{array}$ \\
\hline $\mathbf{6 6 / 6 7}$ & & $\begin{array}{l}\text { Cine en } \\
\text { casa }\end{array}$ & & & & $\begin{array}{l}\text { Cine club } \\
\text { (UHF) }\end{array}$ & $\begin{array}{l}\text { Sesión de } \\
\text { noche }\end{array}$ \\
\hline $\mathbf{6 7 / 6 8}$ & & $\begin{array}{l}\text { Cine en } \\
\text { casa }\end{array}$ & & & & $\begin{array}{l}\text { Cine club } \\
\text { (UHF) }\end{array}$ & $\begin{array}{l}\text { Sesión de } \\
\text { noche }\end{array}$ \\
\hline $\mathbf{6 8 / 6 9}$ & $\begin{array}{c}\text { Filmoteca } \\
\text { Tv }\end{array}$ & $\begin{array}{l}\text { Cine club } \\
\text { (UHF) }\end{array}$ & & & & $\begin{array}{l}\text { Sesión de } \\
\text { tarde }\end{array}$ & $\begin{array}{l}\text { Sesión de } \\
\text { noche }\end{array}$ \\
\hline
\end{tabular}

Fuente: Tele Radio. Elaboración propia

En la primavera de 1969, el número de películas emitidas a la semana aumentó a cuatro gracias al espacio Filmoteca Tv, que podía verse los lunes en la primera cadena y que programaba películas semejantes a las de Cine Club, aunque sin organizarse en ciclos ni emitirse en versión original ${ }^{13}$.

${ }^{13}$ Algunas de las películas emitidas por Filmoteca Tv durante la temporada 68/69 fueron: Infierno en la ciudad, La mujer marcada, El ministro de miedo, Guillermo Tell, Mas allá del bosque, El desafío, Un hombre de paja... 
Pese al enorme interés manifestado por los espectadores, el cine tardó mucho tiempo en tener un espacio consolidado en la parrilla de televisión española. Las trabas de la industria y los problemas técnicos y artísticos hicieron que se programasen pocas películas hasta, al menos, el año 1967 y que, no siempre se respetase su emisión. A partir de esta fecha no solo aumenta la variedad de filmes emitiéndose ciclos de cine de culto además de producciones de entretenimiento sino que, también, se observa una mayor seriedad a la hora de tratar los espacios cinematográficos.

\section{La industria cinematográfica en España y la televisión}

Los españoles manifestaron durante la época de estudio un enorme interés por el cine tal y como muestran las diversas revistas publicadas durante estos años sobre esta cuestión. Los magazines estudiados presentan características muy diferentes. Nuestro cine era una publicación que abogaba por un cine con un cierto compromiso social y, por ello, mantenía un talante crítico ante los planteamientos estatales. En este contexto, la televisión fue tratada exclusivamente en relación a la industria cinematográfica nacional y extranjera ${ }^{14}$.

Primer Plano, la más afín a las directrices oficiales, fue progresivamente convirtiéndose en una revista de curiosidades sobre el mundo del celuloide aunque sin perder sus editoriales de marcado carácter ideológico. La revista creó, desde finales de la década de los cincuenta, un apartado dedicado a la televisión que evidenciaba una cierta postura crítica ante prácticamente todos los programas emitidos ${ }^{15}$.

Con planteamientos más religiosos que políticos, Film ideal, fue principalmente una revista de crítica cinematográfica donde se analizaban las películas proyectados en las pantallas. En 1962 se creó un apartado en el que se comentaban las novedades y las noticias más relevantes sobre la televisión desde la idea de la complementariedad de ambos medios ${ }^{16}$.

A pesar de sus evidentes diferencias, las tres publicaciones compartían una misma visión sobre la televisión: ésta era, o podía llegar a ser, un amenaza para la exhibición cinematográfica y, por ende, para toda la industria ${ }^{17}$.

${ }^{14}$ Esta publicación está más preocupada por el desarrollo del Nuevo Cine o por la falta de datos de taquilla que por el conflicto con la televisión. No obstante sí aparecen algunas referencias a la misma. "En esta década pasada, la industria de Hollywood sufrió una violenta sacudida con la irrupción de la TV, enemiga poderosa que llevaba el espectáculo hasta le interior de los hogares". Nuestro cinema, n 6-7, diciembre 1961.

${ }^{15}$ Durante todo el año 1962, en Primer Plano se publican diversos comentarios sobre los géneros televisivos emitidos por TVE. Prácticamente todos, salvo el tiempo y algunos otros programas, son fuertemente criticados. Sobre los concursos, por ejemplo señala su falta de originalidad e interés (Primer Plano, año XXII, $n^{\circ} 1129,1$ junio 1962) o sobre las películas su antigüedad y mala calidad técnica (Primer plano, año XXII, $n^{\circ} 1119,23$ marzo 1962)

16 "Sucede que mientras la televisión es como el gran fantasma económico del cine, éste es, a su vez, el fantasma artístico, la sombra siempre acechante de la televisión". Film ideal, n 95 , 1 mayo 1962.

${ }^{17}$ Las tres revistas publican diversos comentarios que permiten afirmar esta cuestión: "Así, las repercusiones en nuestro país de la crisis que atraviesa en todas partes el espectáculo cinematográficos; la influencia que, ahora puede comenzar a notarse aquí de la televisión...", 


\subsection{La televisión y la pérdida de espectadores cinematográficos}

El cine español siempre manifestó estar en crisis, incluso desde antes de la llegada de la televisión ${ }^{18}$. Los problemas que éste padeció durante prácticamente todo el franquismo y que afectaron, principalmente, a la calidad -y por tanto a su posibilidad de explotación- de los filmes producidos, tuvieron su origen en la mala organización de la industria tras la contienda.

Pese a la eterna mala racha del séptimo arte español, el público español acudía en masa a las salas de cine a ver películas nacionales y extranjeras hasta mediados de la década de los sesenta. En el año 1966 existían en España 8.193 salas de cine, casi el doble que diez años antes (Diez Puertas, 2003: 40). A partir de ese año se produjo una progresiva disminución del número de pantallas y de espectadores contabilizándose, apenas cuatro años después, mil doscientas salas menos (Ansola, 2003: 4).

Este descenso no fue uniforme. Según un estudio realizado por el Sindicato Nacional del Espectáculo en 1974, en las capitales de provincia se mantuvo el número de cines aumentando incluso en las poblaciones de más de 30.000 habitantes. Las zonas más afectadas fueron las rurales (con un número de habitantes inferior a 5.000) donde prácticamente desaparecieron todas las salas (Cuevas, 1976, 244-245).

Fue la llamada "pequeña explotación", es decir, primero los cines de pueblo y posteriormente los de barrio, los que vieron disminuir de forma alarmante el número de espectadores (Cuevas, 1976: 247). Ambos tipos de salas acabaron cerrando por falta de rentabilidad, aunque por circunstancias diferentes.

En los pueblos, la disminución del número de espectadores fue achacado, en primer lugar, a la televisión. El Sindicato Nacional del Espectáculo señalaba en 1965:

"La exhibición cinematográfica es el sector más directamente afectado por la competencia de la televisión. En la pequeñas poblaciones agrícolas, los cines han cerrado al carecer de un público que se traslade desde el bar, casino o centro parroquial que dispone de televisor." (Montero y Paz, 2012:125).

La afirmación del Sindicato parece responder más a un temor que a una realidad ya que, como se ha visto, 1965 no solo fue un año (el último) en el que el número de salas de cine se hallaba en aumento sino que, en esos momentos, televisión española todavía no emitía en toda la península. (Cantero, 2005: 105-126).

Por otro lado, el texto obvia uno de los problemas más acuciantes a los que tuvo que hacer frente el campo español, la emigración de buena parte de sus habitantes a

Nuestro cine, $\mathrm{n}^{\circ}$ 25, diciembre 1963. "Paso a paso, la televisión de todo el mundo ha ido moviendo sus tentáculos para hacer presa en aquellos ambientes que hasta ahora eran privilegio exclusivo del cine”, Primer Plano $\mathrm{n}^{\circ}$ 1110, 19 enero 1962. “... Entonces los espectadores de cine, los que iban «echen lo que echen» y siempre a mismo cine de barrio -lujoso o nose encuentran con que sin salir de casa pueden divertirse como antes. Y dejan de ir al cine", Film ideal, $n^{\circ}$ 87, año VII, 1 enero 1962.

${ }^{18}$ La revista Nuestro cine abordó esta cuestión diversas ocasiones. En diciembre de 1961, la publicación realizó una encuesta a diversos directores en la que se les preguntaba por la "tantas veces repetida" crisis del cine español y por las causas que, según ellos, la habían provocado. Buena parte de los mismos achacaron los problemas del séptimo arte nacional a la falta de apertura y a la mala organización de la industria. Nuestro cine, n 6-7, diciembre 1961. 
las ciudades con el consiguiente despoblamiento de los pueblos y, por ende, el cierre de sus salas ${ }^{19}$.

Frente a las apreciaciones del Sindicato Nacional de Espectáculo, los estudios realizado en 1965 sobre la influencia de la televisión en la sociedad (Estudio sobre los medios de comunicación de masas en España, 1965) ofrecían otros resultados.

Según las encuestas en 1965 la televisión no era, todavía, una costumbre. Solo el $40 \%$ de quienes solían verla lo hacían todos los días. El resto, dos o tres veces por semana (15\%) o con menor frecuencia (33\%) (Del Campo, 1968: 172-174). El consumo de televisión, que se hacía mayoritariamente por la noche (87\% de los consumidores) no era, como puede verse, muy acusado.

Los datos recogidos señalan que, el televisor, en los años centrales de la décadas de los 60, era todavía un objeto propio de poblaciones urbanas con ingresos fijos. El espectador medio era un varón joven con estudios y una posición económica desahogada. Poco que ver con el habitante rural descrito en el texto.

En 1962, Nuestro cine viajó a Quismondo, un pueblo de la provincia de Toledo, para conocer los gustos de los espectadores y los problemas de las salas rurales. En ningún momento de las entrevistas realizadas a los ciudadanos de esta localidad se aborda la cuestión de la televisión aunque sí se menciona el elevado número de jóvenes que han emigrado a la ciudad y el baile como el principal competidor del séptimo arte al que muchos acuden por falta de alternativas (Nuestro cine, $\mathrm{n}^{0} 8$, febrero 1962)

Esta cuestión no se modificó en toda la década. Según señala el Estudio General de Medios de 1969, en las poblaciones con menos de cinco mil habitantes casi un $40 \%$ de la población afirmaba no ir nunca al cine y tan solo un $21 \%$ de los encuestados habían asistido en la última semana. De estos, del supuesto público semanal, solamente poseían un televisor un $46,1 \%$ de la población ${ }^{20}$. Estos datos corroboran dos cuestiones. Por un lado, el progresivo abandono del cine como uno de los principales elementos de ocio y, por el otro, la todavía insuficiente relevancia de la televisión en el medio rural español y, por tanto, su escasa influencia en la pérdida de salas.

En las ciudades, la evolución de la exhibición cinematográfica sufrió un proceso lento pero evidente. En 1965, la mayor parte de los madrileños (64\%) acudían al cine al menos una vez al mes. Cuatro años más tarde tan solo lo hacían el 49\%. (Estudio General de Medios, $1^{\circ}$ oleada, abril 1969, p. 103)

En 1967, el informe anual sobre cine español reveló uno de los motivos de la pérdida de espectadores cinematográficos: la competencia de espectáculos deportivos, taurinos y cinematográficos que, "se pasan por la pequeña pantalla de televisión durante las horas que corrientemente están funcionando los cines" (Sindicato nacional del espectáculo. Cine español 1967, p. 2)

\footnotetext{
19 “Ahora bien, hay un tipo de población rural en la que se junta el absentismo del campo con la emigración de la parte más vital de sus habitantes, circunstancias que impiden e impedirán toda medida vitalizadora para mantener abiertas las salas". Sindicato nacional del espectáculo. Cine español, 1966, p. 7.

${ }^{20}$ El porcentaje disminuye en las poblaciones con menos de 2000 habitantes donde tan solo un 38,8\% posee un televisor. Estudio General de Medios, $1^{\circ}$ oleada, abril 1969, p. 112.
} 
Este dato concuerda temporalmente, tal y como se ha señalado, con el aumento del número de largometrajes en televisión y la consolidación de sus fechas y horas de emisión. Así como con la disminución de la asistencia de los espectadores a las salas de las grandes ciudades. No en vano, el 39\% de los telespectadores reconocían, tan solo un par de años antes, haber disminuido la frecuencia de asistencia al cine por culpa de la televisión. (Estudio sobre los medios de comunicación de masas de España, p. 194).

Varias son las fuentes que corroboran también esta cuestión, como aquellas que plantean las quejas de los empresarios por el horario de emisión de los largometrajes en televisión al que relacionan con la falta de público urbano ${ }^{21}$.

En España, el proceso de reducción del público cinematográfico fue más pausado que en el resto de Occidente. Los primeros datos significativos se observan casi catorce años después de las primeras emisiones televisivas y, según indican las fuentes, se producen en los cine rurales y de barrio, es decir, en las salas que programaban películas antiguas muy alejadas de los circuitos comerciales del momento.

Éste tipo de películas, producidas entre los años 40 y 50 tanto en España como en el extranjero, eran semejantes a los filmes que, por estas fechas, solían programar -al menos en su primera cadena- televisión española.

Aunque sin responder al esquema desarrollado en otros países, la instauración de la televisión fue uno de los elementos que influyó en la disminución de espectadores en los cines de barrio a partir de los años finales de la década de los sesenta ${ }^{22}$. A éstos se solía acudir a ver, por poco dinero, alguna película. Lo importante no era tanto el título de la obra como el hecho de entretenerse viendo un filme, aunque este fuese antiguo (Montero y Paz, 2012: 84-85). La programación de televisión, que emitía largometrajes de estas características, evidenció lo innecesario de estos locales a medida que la población accedía a los aparatos de televisión.

Este proceso es similar al ocurrido en EEUU, teniendo en cuenta las características específicas de cada cine. En Norteamérica, existía todo un engranaje en la industria del cine que producía películas de serie B. Éstas, que servían de complemento en los programas dobles, solían resultar más o menos lucrativas. No se alcanzaban elevadas recaudaciones pero sí se superaban claramente sus costes.

${ }^{21}$ Esta idea aparece en diversos documentos, en 1966 las conclusiones de la asamblea de empresarios de poblaciones menores de 5.000 habitantes pidió, entre otras cuestiones, la coordinación de horarios entre la televisión y el resto de los espectáculos Sindicato nacional del espectáculo. Cine español, 1966, p. 7. Este fue también uno de los temas tratados en las Comisiones creadas por el subsecretario de Información y Turismo en 1969 con el fin de abordar los problemas que la televisión ocasionaba al cine. José María Otero, TVE: Escuela de cine. Festival de Huesca, Huesca, 2006, p. 29.

22 Una encuesta realizada a los empresarios en el año 1974 por el Sindicato Nacional del Espectáculo y la agrupación de empresarios de cine en la que se analizaban las causas del descenso de espectadores y, por tanto, del cierre de algunas salas de cine. Según las respuestas, éstas se debían, en primer lugar, a la competencia de la televisión, seguida del aumento del precio de la entrada, la popularización del coche y la emigración. Sindicato nacional del espectáculo. Cine español, 1975, p. 11. 
La llegada de la televisión acabó con este tipo de películas que, poco a poco, fueron convirtiéndose en seriales televisivos (Baget, 1975: 15). El público continuó asistiendo, en mayor o menor medida, a los estrenos pero dejó de acudir a este tipo de salas.

El proceso, tal y como anunciaba en tono belicoso la revista Tele Radio en 1963, fue muy claro:

“...Ciertamente, la televisión resta público al cine. Al cine malo, por supuesto. Las grandes películas, las buenas películas las verdaderas películas, acaso hayan incrementado sus taquillas desde el momento del advenimiento de la televisión. Con ella ya no se hace preciso acudir a una sala de cinematografía en la que se proyecta una película carente de todo interés, simplemente "para pasar el rato" (Tele Radio No 311, 9 al 15 de diciembre 1963)

Sin embargo y aunque la televisión tuvo relación con esta cuestión, lo cierto es que las formas de ocio habían variado sustancialmente en los años sesenta ampliándose enormemente las posibilidades de diversión tal y como se comentaba en la revista Tele Radio:

"Hoy, los sociólogos han ido apuntando las muchas y diversas causas que han determinado el paulatino alejamiento del público del cine que se ofrece en las salas comerciales, desde el fenómeno del automóvil, con la evasión al aire libre en los fines de semana, hasta un afán de superación cultural que hace que el público sea perezoso, salvo que las cosas le atraigan poderosamente." (Tele Radio $\mathrm{n}^{\circ} 45726$ de septiembre al 2 octubre 1965)

Por otro lado, el cine ya no era el entretenimiento más barato, especialmente tras la subida de las entradas a finales de los 60 .

El público español de los sesenta, tal y como señalan las cifras, se volvió más selectivo a la hora de acudir a los cines. Esto hizo que, poco a poco y a medida que los televisores se hacían más asequibles, los cines de barrio dejaran de tener su razón de ser: entretener durante algunas horas y por un precio razonable al público proyectando películas antiguas. Películas que ahora podían ver en el televisor.

\section{Conclusiones}

A pesar del sentimiento de triunfo con el que se presenta la televisión frente al cine desde su origen, no se puede decir que ésta fuera una verdadera competidora, por lo menos hasta finales de los sesenta. Por un lado, el precio de los televisores provocó que muchos españoles tuvieran que esperar varios años para poder comprarse el tan anhelado aparato. Por otro, la asistencia al cine era durante estos años una costumbre muy arraigada, especialmente los fines de semana. El desfavorecido tratamiento que recibían los largometrajes en televisión -mala calidad, repetición de películas, cambios en la programación- hasta los años centrales de la década de estudio no facilitaron, por otra parte, que se observase a la pequeña pantalla como una sustituta adecuada para el séptimo arte.

Frente a las naciones occidentales, donde el proceso de pérdida de espectadores fue rápido y evidente ${ }^{23}$, en España, la peculiar organización de la industria cinematográ-

${ }^{23}$ En 1965 España todavía tenía los índices más altos de asistencia al cine. Sindicato nacional del espectáculo. Cine español, 1966, p. 8. 
fica, unida a una compleja situación económica y social, ocasionaron un proceso mucho mas lento dirigido a salas muy concretas.

En primer lugar se perdieron las pantallas de los pueblos debido, principalmente, a la emigración rural y a los cambios económicos y sociales acaecidos estos años. La televisión, tal y como muestran los documentos consultados, no tuvo verdadera relevancia en este hecho, al menos durante los años de estudio.

Posteriormente se fueron cerrando las salas de barrio de las ciudades. Uno de los motivos que ocasionó la clausura de estos locales fue, tal y como señalan diversas fuentes, la competencia de la televisión, más concretamente la emisión de largometrajes ${ }^{24}$. Aunque, desde luego, esta no fue la única razón.

Los años sesenta fueron la década del desarrollismo económico que propició el aumento de las posibilidades de diversión y el abandono de aquellas que ya no resultaban útiles o adecuadas. Una de ellas fue el baile, que solía celebrarse las tarde de los domingos y que fue sustituido en los 60 por salidas nocturnas a discotecas o por los famosos guateques (Pallarés y Freixa, 2000: 23-41). Otra fue, como se ha visto, la asistencia a los cines cuyo declive estuvo marcado por las nuevas formas de ocio.

Los largometrajes emitidos en televisión ayudaron a los espectadores urbanos a cubrir su afición por el cine y les hizo ser, de alguna manera, más selectivo a la hora de acudir a los locales de exhibición. Según señalan las cifras, el público continuó acudiendo a las salas a ver en pantalla grande los estrenos más señalados lo que demuestra que, si bien la televisión, no resultó ser el terrible rival que auguraban las fuentes desde el origen, sí pudo contribuir, al menos desde los primeros años de la década de los setenta, a modificar la forma en la que los españoles acudían al cine.

\section{Referencias}

ABRAMSON, Albert (2003): The History of Television 1942 to 2000. North Carolina, McFarland \& Company.

AIMC (1998): Estudio General de Medios, CD room 1, 1968-1977.

ANSOLA GONZÁLEZ, Txomin (2002): "Génesis y primeras repercusiones de la crisis del espectáculo cinematográfico en Álava (1968-1978)" en Sancho el sabio: Revista de cultura e investigación vasca, $\mathrm{n}^{\mathrm{o}}$ 19, pp. 167-186

BAGET, José María (1965): Televisión un nuevo arte. Madrid, Rialp.

BAGET, José María (1975): 18 años de TVE. Barcelona, Diáfora S.A.

BAGET, Josep María (2001): "El legado de la televisión franquista". Formats, revista de comunicación audiovisual, $\mathrm{n}^{0} 3$.

BAZIN, André (1953): "Will the cinemascope save the film industry?" Film filosophy, vol. $6, \mathrm{n}^{\circ} 2$, enero 2002.

24 "Domingos y lunes eran auténticamente esperados con la esperanzada ilusión de que la película larga fuera decorosa, al menos, y casi nos atreveríamos a asegurar que las noches de os lunes podían notarse en las taquillas de los cines, sobre todo los de barrio, debido al goloseo de poder ver una buena película en bata y zapatillas ante la pantalla del televisor". Primer plano, año XXII, n 1119, 23 marzo 1962. 
CANTERO, Chus (2005) "Equipamientos culturales de proximidad en España en el siglo XX. Los teleclubs" Periférica. Revista para el análisis de la cultura y el territorio, $\mathrm{N}^{\mathrm{o}}$ 6, pp., 105-126.

CUEVAS, Antonio (1976): Economía cinematográfica. La producción y el comercio de películas. Madrid, Antonio Cuevas.

CUEVAS, Antonio (1994): Las relaciones entre el cinema y la televisión en España $y$ otros países de Europa. Madrid, Egeda.

DEL CAMPO, Salustiano (1968): Cambios sociales y formas de vida. Madrid, Ariel

DIEZ PUERTAS, Emeterio (2003): Historia social del cine en España. Madrid, Fundamentos.

HANKARD, Maurice (1965): La radio y la televisión en Europa. Quito, Ciespal.

I.O.P. "Estudio sobre los medios de comunicación de masas en España”, Madrid, 1963-1964, 3vols, I. O. P. El público opina sobre televisión, Madrid, 1965

MAY, Renato (1959): cine y televisión. Madrid, Rialp.

MONTERO, Julio y RUEDA, José Carlos (2001): Introducción a la Historia de la comunicación Social. Barcelona, Ariel.

MONTERO DÍAZ, Julio y PAZ, María Antonia (2012): Lo que el viento no se llevó. Madrid, Rialp.

MORENO TORRES, Luis (2005): "Cine y televisión. Las amistades peligrosas". Comunicar, $\mathrm{n}^{\circ} 25,2$.

PALACIO, Manuel (2005): Historia de la televisión. Barcelona, Gedisa.

PALLARÉS, Joan y FREIXA, Carles (2000): "Espacios e itinerarios para el ocio juvenil nocturno". Estudios de juventud, n ${ }^{\circ}$ 50/00, pp. 23-41

OTERO, José María (2006): TVE: escuela de cine. Huesca, Instituto de estudios aragoneses.

RODRÍGUEZ MÉNDEZ, José Luis (1971): Los teleadictos. Barcelona, Estela.

ROMAGUERA, Joaquim y ALSINA, Homero (eds.,1998): Textos y manifiestos. Barcelona, Cátedra.

SINDICATO NACIONAL DEL ESPECTÁCULO (1966): Cine español 1966. Madrid, Ediciones y publicaciones populares.

SINDICATO NACIONAL DEL ESPECTÁCULO (1967): Cine español 1967. Madrid, Ediciones y publicaciones populares. 